\title{
Properties of $\mathrm{Ni}_{3} \mathrm{Fe}$ Nanoparticles Prepared by Chemical Method
}

\author{
K. ZÁbranskÝ*, O. Schneeweiss, N. PizŮrová and B. David \\ Institute of Physics of Materials, Academy of Sciences of the Czech Republic \\ Žižkova 22, CZ-616 62 Brno, Czech Republic
}

\begin{abstract}
$\mathrm{Ni}_{3} \mathrm{Fe}$ nanoparticles prepared by calcination of the iron-nickel oxalate were investigated by X-ray diffraction, Mössbauer spectroscopy and magnetic measurements. The high temperature X-ray diffraction shows two stages of transformation of oxalate: (i) amorphization and (ii) formation of nanocrystalline $\mathrm{Ni}_{3} \mathrm{Fe}$ particles. The development of coercivity, magnetization and mean coherence length $(\approx$ particle size $)$ is discussed.
\end{abstract}

PACS numbers: 61.05.cp, 61.46.-w, 75.20.En, 75.50.Bb

\section{Introduction}

$\mathrm{Ni}_{3} \mathrm{Fe}$ alloy is well-known for their good soft magnetic properties. The bulk $\mathrm{Ni}_{3} \mathrm{Fe}$ phase crystallizes in fcc structure and its magnetic properties depend on atomic ordering [1]. Several methods for preparation of this material in nanocrystalline form e.g. ball milling, chemical synthesis, etc., have been recently developed [2-5]. In this paper we present the preparation of the nanocrystalline $\mathrm{Ni}_{3} \mathrm{Fe}$ using solid state decomposition.

\section{Experimental details}

The $\mathrm{Ni}_{3} \mathrm{Fe}$ nanocrystalline powder was prepared by the calcination of $\mathrm{Ni}_{0.75} \mathrm{Fe}_{0.25} \mathrm{C}_{2} \mathrm{O}_{4}$. The phase analysis of the samples was carried out by X-ray diffraction (XRD) using Co $K_{\alpha}$ radiation at room temperature (RT) and at high temperature (HT) in the furnace with $\mathrm{H}_{2}$ atmosphere where the precursor was deposited on heating platinum strip. The XRD patterns were taken in the temperature range $100 \div 600{ }^{\circ} \mathrm{C}$ with the step $\Delta T=20^{\circ} \mathrm{C}$. The mean coherence length $(\mathrm{MCL})(\approx$ particle size) was calculated using the Scherrer formula from the XRD patterns. The magnetic measurements were performed by vibration sample magnetometer (VSM) EG\&G model No. 4500 Princeton Applied Research Corporation. Hysteresis loops were measured at RT. The magnetic field was increased from the 0 to $796 \mathrm{kA} / \mathrm{m}$ with the step of $3.2 \mathrm{kA} / \mathrm{m}$. Thermomagnetic curve (TMC) was measured in the temperature range $25 \rightarrow 800 / 30 \mathrm{~min} \rightarrow 25^{\circ} \mathrm{C}$ under $\mathrm{H}_{2}$ atmosphere with the temperature sweep $4{ }^{\circ} \mathrm{C} / \mathrm{min}$ in the magnetic field $H=4 \mathrm{kA} / \mathrm{m}$. Transmission electron microscopy (TEM) and energy dispersive X-ray analysis (EDAX) were used for the determination of the chemical composition.

\section{Results and discussions}

The RT XRD patterns of the precursor sample show $\mathrm{Fe}-\mathrm{Ni}$ oxalate compound with traces of impurities remaining from precursor preparation. Two stages of transformation of the precursor to nanocrystalline powder

* corresponding author; e-mail: zabransky@ipm.cz were observed by HT XRD measurement. The first stage begins at $160^{\circ} \mathrm{C}$ where an amorphization occurs. It is represented by broad peaks in the XRD patterns. The second stage starts at $260^{\circ} \mathrm{C}$ and it is characterized by appearing of crystalline fcc NiFe phase. The intensity of the diffraction peaks and MCL increases with the increasing annealing temperature. The temperature dependence of MCL is depicted in Fig. 1 where two stages of MCL growth of the nanocrystalline NiFe phase can be recognized.

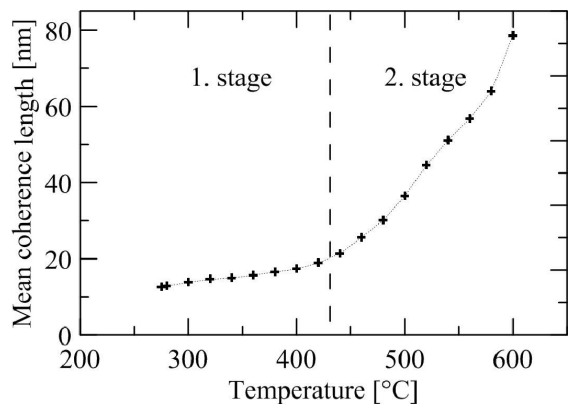

Fig. 1. The mean coherence length MCL in dependence on temperature.

The slight increase up to $\approx 420^{\circ} \mathrm{C}$ is followed by a more pronounced increase at higher temperature. Similarly, a rapid slope can be observed on TMC at $\approx 370^{\circ} \mathrm{C}$ (Fig. 2) with the maximum at the same temperature $\left(\approx 420^{\circ} \mathrm{C}\right)$ where the pronounced increase in MCL begins. The decrease in magnetic moment above this temperature is connected with the MCL growth and increase in magnetocrystalline anisotropy of crystalline $\mathrm{Ni}_{3} \mathrm{Fe}$ phase. The Curie temperatures $\left(T_{\mathrm{C}}\right)$ determined from the TMC are $600^{\circ} \mathrm{C}$ for the increasing temperature and $610^{\circ} \mathrm{C}$ for the cooling. The difference is probably associated with structural changes at high temperature up to $800^{\circ} \mathrm{C}$. The reported $T_{\mathrm{C}}$ of the bulk $\mathrm{Ni}_{3} \mathrm{Fe}$ phase is $600^{\circ} \mathrm{C}$ for a disordered state and $690^{\circ} \mathrm{C}[1]$. Therefore the shift of the $T_{\mathrm{C}}$ on TMC between increasing and decreasing temperature can be related to a derivation from the stoichiometric composition towards a higher iron concentration and with changes in atomic ordering $[6,7]$. This was con- 


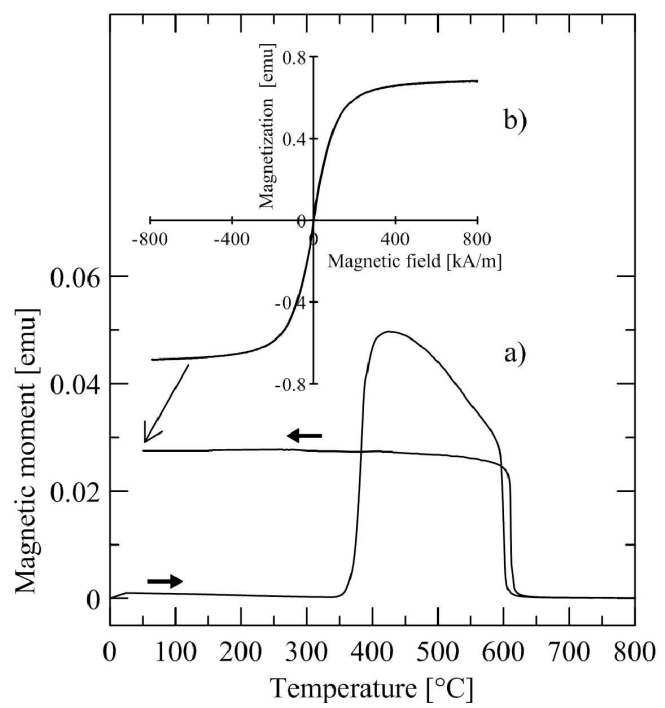

Fig. 2. (a) Temperature dependence of the magnetic moment of the precursor by the annealing in $\mathrm{H}_{2}$ atmosphere. The arrowheads indicate the increase and decrease of the temperature. (b) The hysteresis loop of the sample after TMC measurement.

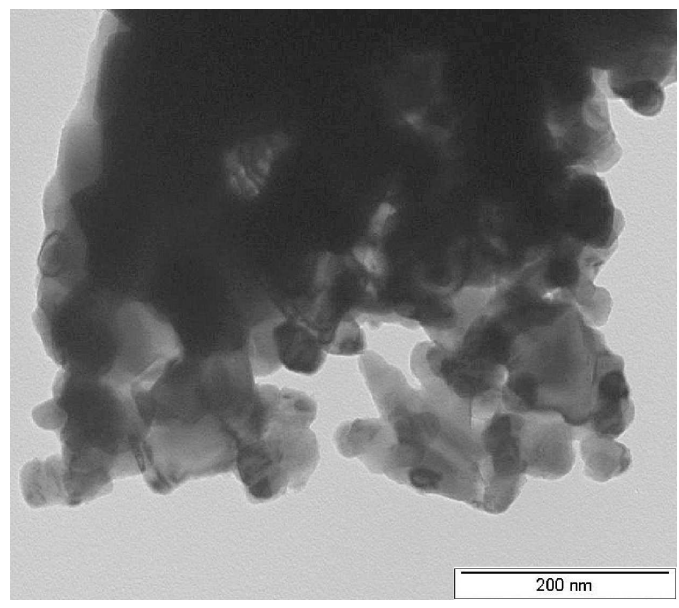

Fig. 3. TEM image of the sample after the annealing at $560{ }^{\circ} \mathrm{C}$ in $\mathrm{H}_{2}$ in the furnace.

TABLE

The parameters of the hysteresis loops taken after the different heat treatments of the precursor in $\mathrm{H}_{2}$ (coercivity, $H_{\mathrm{c}}$, saturation magnetization $\sigma_{\mathrm{s}}$, remanent magnetization $\sigma_{\mathrm{r}}$ ).

\begin{tabular}{l|c|c|c}
\hline \hline \multicolumn{1}{c|}{ Heat treatment: after } & $H_{\mathrm{c}}[\mathrm{kA} / \mathrm{m}]$ & $\sigma_{\mathrm{s}}[\mathrm{T}]$ & $\sigma_{\mathrm{r}}[\mathrm{T}]$ \\
\hline TMC measurement up to $800^{\circ} \mathrm{C}$ & 1.01 & 1.32 & 0.173 \\
HT XRD up to $600{ }^{\circ} \mathrm{C}$ & 4.87 & 1.30 & 0.135 \\
furnace annealing up to $560^{\circ} \mathrm{C}$ & 9.98 & 1.25 & 0.141
\end{tabular}

firmed by EDAX measurement taken in TEM where the mean chemical composition of the nanocrystalline particles $62.6 \pm 0.4$ at.\% $\mathrm{Ni}$ and $37.4 \pm 0.4$ at.\% Fe was determined.
The TEM image in Fig. 3 shows the nanoparticles after annealing at $560^{\circ} \mathrm{C}$ in $\mathrm{H}_{2}$.

The results from hysteresis loops measurement are summarized in Table. The $\sigma_{\mathrm{s}}$ value taken on the sample after the annealing at $560^{\circ} \mathrm{C}$ in $\mathrm{H}_{2}$ corresponds to chemical composition $\mathrm{Fe}_{40} \mathrm{Ni}_{40}$ reported in [8]. This is in a good agreement with the values determined by TEM. Higher values of $\sigma_{\mathrm{s}}$ and lower $H_{\mathrm{c}}$ were found on the samples annealed at higher temperatures. It can be ascribed to an increase in particle size $[9,10]$ and atomic ordering, respectively.

\section{Conclusions}

$\mathrm{Ni}_{3} \mathrm{Fe}$ nanoparticles were prepared by the calcination of nickel-iron oxalate precursor. The data derived from XRD and TMC measurements indicate two stages of the particle growth. The slight increase in MCL up to $\approx 420^{\circ} \mathrm{C}$ is followed by a more pronounced increase at higher temperatures. The maximum magnetic moment was observed at $\approx 420^{\circ} \mathrm{C}$. The higher annealing temperature the higher saturation magnetization $\sigma_{\mathrm{s}}$ and lower coercivity $H_{\mathrm{c}}$ were found which can be explained as the result of an increase in particle size and atomic ordering.

\section{Acknowledgments}

This work was supported by the Ministry of Education, Youth and Sports of the Czech Republic (project No. 1M6198959201) and by the Grant Agency of the Czech Republic (project No. 106/08/1440).

\section{References}

[1] L.J. Swartzendruber, V.P. Itkin, C.B. Alcock, in: Phase Diagram of Binary Iron Alloys, Ed. H. Okamoto, ASM International, Materials Park, $\mathrm{OH}$ 1993, p. 256.

[2] I. Chicinas, V. Pop, O. Isnard, J. Magn. Magn. Mater. 242-245, 885 (2002).

[3] A. Datta, M. Pal, D. Chakravorty, D. Das, S.N. Chintalapudi, J. Magn. Magn. Mater. 205, 301 (1999).

[4] I. Chicinas, V. Pop, O. Isnard, J.M. LeBreton, J. Juraszek, J. Alloys Comp. 352, 34 (2003).

[5] P. Kollar, D. Oleksakova, J. Fuzer, J. Kovac, S. Roth, K. Polanski, J. Magn. Magn. Mater. 310, 2609 (2007).

[6] R.J. Wakelir, E.L. Yates, Proc. Phys. Soc. 66, 221 (1953).

[7] G. Inden, Z. Metallkd. 66, 577 (1975).

[8] Magnetic Properties of Metals. D-Elements, Alloys and Compounds, Ed. H.P.J. Wijn, Springer-Verlag, Berlin 1991, p. 33.

[9] G. Herzer, Scr. Metal. Mater. 33, 1741 (1995).

[10] E. Artz, Acta Mater. 46, 5611 (1998). 